\title{
A Compact Umbrella-Shaped UWB Antenna with Gain Augmentation Using Frequency Selective Surface
}

\author{
Surajit KUNDU ${ }^{1}$, Ayan CHATTERJEE ${ }^{1}$, Sanjay Kumar JANA ${ }^{1}$, Susanta Kumar PARUI ${ }^{2}$ \\ ${ }^{1}$ Dept. of ECE, National Institute of Technology Sikkim, Ravangla, South Sikkim, India \\ ${ }^{2}$ Dept. of ECE, Indian Institute of Engineering Science and Technology, Shibpur, Howrah, India \\ surajit.kundu@nitsikkim.ac.in, ayanmrinal26@gmail.com,skjnit@nitsikkim.ac.in, arkapv@yahoo.co.in
}

Submitted September 3, 2017 / Accepted November 22, 2017

\begin{abstract}
A compact $(35 \mathrm{~mm} \times 30 \mathrm{~mm} \times 0.8 \mathrm{~mm})$ co-planar waveguide fed ultra-wideband antenna with bended ground plane suitable for GPR applications is proposed in this article. The umbrella shaped radiating element is constructed using the intersection of two ellipses. The proposed antenna provides a wide impedance bandwidth of $10.35 \mathrm{GHz}(3.05-13.4 \mathrm{GHz})$ covering the unlicensed UWB band. The simply structured antenna is easy to fabricate and to integrate in $P C B$ board. A frequency selective surface (FSS) with two layers, each of $4 \times 4$ array, cascaded via air gap, is incorporated in the antenna as a substrate to enhance the gain by 2 to $4 \mathrm{dBi}$ over the entire frequency band. Metamaterial inspired unit cells are chosen for the FSS layers, with unit cell dimension on the order of $\lambda / 10$ with respect to $3 \mathrm{GHz}$, much less than $\lambda / 4$. The spacing between the antenna and FSS is kept so as to enhance the gain value without hampering nearly flat gain response over the band. The gain is maintained between 5.5-8.5 dBi over the band. The antenna was investigated by comparing the simulated and measured fundamental antenna parameters. High radiation efficiency of more than $90 \%$ with non-varying group delay and nearly omnidirectional $\mathrm{H}$ plane radiation pattern were achieved. Measurement results validated the antenna performance and gain enhancement due to the addition of FSS layers.
\end{abstract}

\section{Keywords}

Ultra-Wideband (UWB), Co-Planar Waveguide (CPW), umbrella shaped radiator, Frequency Selective Surface (FSS), gain enhancement

\section{Introduction}

Ultra-wideband technology got the interest of researchers due to its ability to transmit large amount of data with low transmission power in the short range indoor and outdoor wireless communication [1-4]. An unlicensed spectrum of $7.5 \mathrm{GHz}(3.1-10.6 \mathrm{GHz})$ is available for UWB communication as allocated by the Federal Communications Commission in February, 2002. To differentiate it from other communication applications in this wide band, FCC also allocates Power mask that is max. of
$-41.3 \mathrm{dBm} / \mathrm{MHz}$ for indoor and outdoor applications [5]. UWB devices are defined as devices having bandwidth more than or equal to $500 \mathrm{MHz}$, whereas in terms of fractional bandwidth it should be $20 \%$ more than central frequency.

UWB antennas are widely used in impulse radar like ground penetrating radar (GPR), medical imaging applications and short range wireless personal area networks where lower gain of conventional planar UWB antenna is a major constraint [6-13]. Maximum radiation in the broadside direction is much more useful than monopole like bi-directional or omni-directional radiation of conventional UWB antenna. High antenna gain and maximum radiation in the broadside direction can enhance the penetration depth of the transmitted electromagnetic wave from GPR transmitting antenna. This enhancement is an important solution to overcome the higher soil attenuation with increasing frequency of operation. Also wider operational bandwidth needs to maintain as it improves the lateral resolution of GPR. In general, antenna array is used to achieve higher broadside gain but designing wideband, especially ultra-wideband power divider is difficult. With the conventional Wilkinson power divider fractional bandwidth becomes narrow. Wideband response can be achieved by cascading multiple matching networks at the output ports of a single-stage power divider, however the overall size is increased with more resistors, needed for good isolation [24]. Similar problems arise in case of ultrawideband power divider design. Metallic reflectors can be used below the antenna for the purpose, however as the spacing between antenna and the reflector is fixed, this kind of arrangement is not capable of producing enhanced radiation over a wide bandwidth. To overcome these problems periodic structures like Partially Reflective Surfaces (PRS) and Frequency Selective Surfaces (FSS) are being used nowadays in place of solid metallic reflectors [14-18]. Alexandros P. Feresidis et al. proposed a FSS-based Artificial Magnetic Conductor (AMC) operating at $22 \mathrm{GHz}$ placed surrounding a patch antenna [14]. The antenna with the AMC achieved a high gain of $20 \mathrm{dBi}$. The use of a FSS with Jerusalem cross shaped elements as a substrate below the radiating element to improve its bandwidth as well as gain at $2.45 \mathrm{GHz}$ and $5.8 \mathrm{GHz}$, was proposed by Hsing-Yi Chen and Yu Tao [15]. In all such works the enhancement 
of gain was limited to a narrow bandwidth. In 2013, Wanchen Yang et al. proposed a periodic structure [16] with linear reflection phase response, that was used as a substrate in a patch antenna leading to an enhanced gain around $9.36 \mathrm{dBi}$ in a wide bandwidth of $11.76 \%$ over 7.2 to $8.1 \mathrm{GHz}$, for the single element. Apart from conventional designs, metamaterial-inspired periodic structures have also been used for the performance improvement of narrowband or wideband antennas [25-27].

A compact umbrella shaped ultra-wideband antenna is proposed in this article. An enhancement in the antenna gain by 2 to $4 \mathrm{dBi}$ and directional radiation pattern over a wide impedance band of 3.05-13.4 GHz are achieved using a dual-layer FSS placed below the antenna. The distance between antenna and FSS layers are optimized for a higher gain and a suitable impedance matching over the frequency range of operation. For optimization, a distance of half wavelength corresponding to the center frequency around $6.5 \mathrm{GHz}$ is chosen first, followed by rigorous simulation. This will be discussed in detail in Sec. 4. In this paper introduction in Sec. 1 is followed by the design principle of antenna and the FSS layers in Sec. 2 and 3. Section 4 thereafter includes the simulated and measured results of the fundamental antenna parameters along with some parametric studies followed by the conclusion in Sec. 5 .
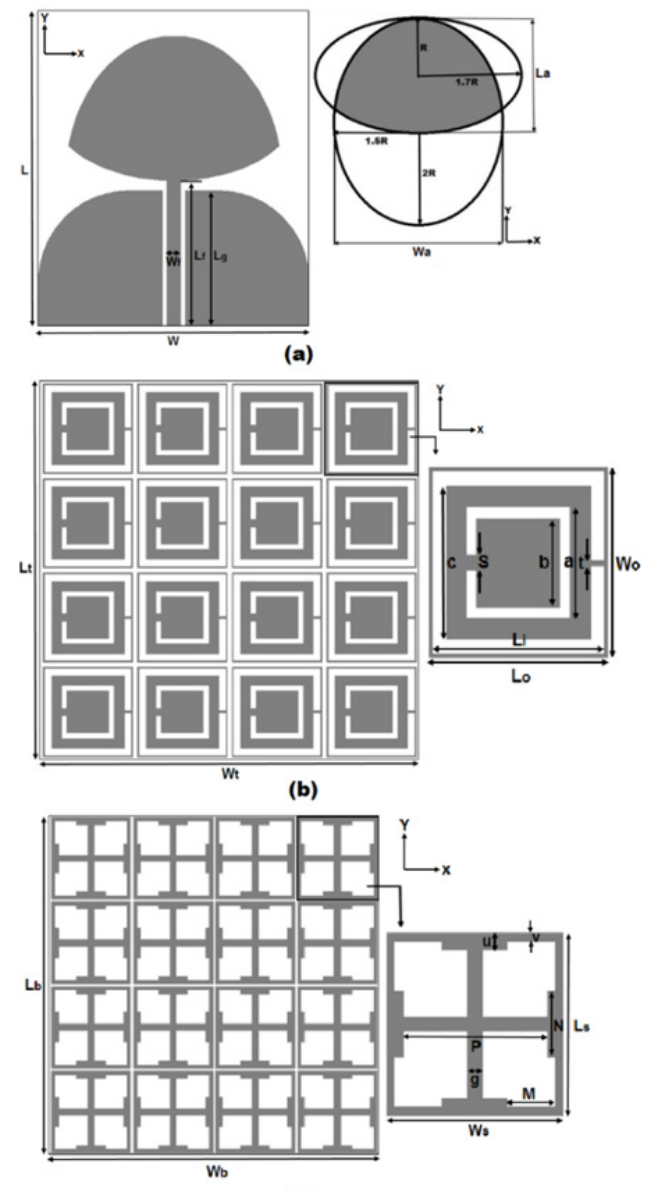

(c)

Fig. 1. A schematic view of the (a) antenna with umbrella shaped radiator, (b) FSS top layer and (c) FSS bottom layer.

\section{Antenna Design}

Circular disk monopole (CDM) antenna gained rapid popularity among UWB researchers due to its simple construction, compactness and flexibility to work for various UWB applications [6-8]. Multiple novel shapes such as rugby ball [19], Mickey mouse antenna [20] were invented earlier by modifying this conventional CDM. Compared to circular disk shape, elliptical shape can enhance the effective length of antenna radiator without affecting the simplicity and compactness of CDM. A schematic of the proposed umbrella shaped monopole antenna is shown in Fig. 1.(a). Umbrella shape was achieved by intersecting two ellipses that are having semi-major axis of $1.7 R$ and $2 R$ and semi-minor axis of $R$ and $1.5 R$ respectively. The value of $R$ was calculated from the following equation: $R=1 / 3 \times \lambda_{\mathrm{L}} / 4$ where $\lambda_{\mathrm{L}}=c / f_{\mathrm{L}}$. Here $f_{\mathrm{L}}$ was taken as lower frequency of unlicensed UWB band that is $3.1 \mathrm{GHz}$, and $c$ indicates speed of light. Co-planar wave guide fed was considered to make the design simple and planar. Bending was introduced at the upper corners, away from feed line that minimizes the ground plane radiations. The proposed antenna was printed on FR4 substrate of thickness $0.8 \mathrm{~mm}$, relative permittivity 4.4 and loss tangent of 0.02 . The antenna feed line was connected with a $50 \Omega$ SMA connector. The fabricated prototype is shown in Fig. 2(a). The optimal dimensions of the proposed antenna are given in Tab. 1.

\begin{tabular}{|c|c|c|c|}
\hline Parameter & Value & Parameter & Value \\
\hline$L$ & $35 \mathrm{~mm}$ & $W_{\mathrm{f}}$ & $1.6 \mathrm{~mm}$ \\
\hline$W$ & $30 \mathrm{~mm}$ & $H$ & $0.8 \mathrm{~mm}$ \\
\hline$L_{\mathrm{g}}$ & $15.2 \mathrm{~mm}$ & $L_{\mathrm{a}}$ & $16.06 \mathrm{~mm}$ \\
\hline$L_{\mathrm{f}}$ & $16.2 \mathrm{~mm}$ & $W_{\mathrm{a}}$ & $24.09 \mathrm{~mm}$ \\
\hline
\end{tabular}

Tab. 1. Optimal dimensions of the proposed antenna.

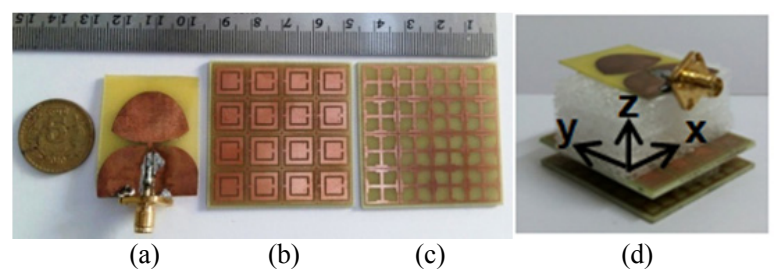

Fig. 2. Fabricated prototypes of the (a) antenna, (b) upper layer of FSS, (c) lower layer of FSS, (d) antenna with FSS.

\section{Design and Analysis of FSS}

A reflective FSS is designed followed by the antenna in the unlicensed UWB spectrum. To achieve reflection in this range the FSS needs to exhibit reflection coefficient $\left(\mathrm{S}_{11}\right)$ near $0 \mathrm{~dB}$ and thus the transmission coefficient $\left(\mathrm{S}_{21}\right)$ below $-10 \mathrm{~dB}$ over the frequency band. During simulation, the port 1 is placed above the top layer of FSS, and the port 2 is placed below the bottom layer of FSS, and the FSS layers are shown in Fig. 1. The FSS being reflective in nature, needs to be placed below the bi-directional radiator at a specific distance as can be seen from Fig. 2(d). The waves radiated by the antenna and thereafter getting reflected by the FSS undergo change in the phase. The re- 
flection phase response is thus a significant parameter in the proposed design.

The proposed FSS is composed of two layers separated by air gap as can be seen from Fig. 2(d). In the proposed design, patch type FSS has been chosen for band stop response in operating frequency band leading to a partially reflecting surface. The layers of the dual-layer FSS are designed on FR4-based substrate having dielectric constant 4.4 and loss tangent of 0.02 . A schematic of the upper layer is shown in Fig. 1(b) with a $4 \times 4$ array and the unit cell geometry. The upper layer consists of a square patch loaded with two split ring shaped square slots of different dimensions as shown in Fig. 1(b). With the introduction of slots, the current excited on surface of unit cell of the FSS is forced to flow surrounding the slots as shown in Fig. 6. In this way the path length for current flow is increased, and the effective wavelength is also increased, leading to a reduced resonance compared to that for the patch without slot. The dimensions of the unit cell in the upper layer of FSS are listed in Tab. 2.

The slots are chosen so as to achieve two resonating frequencies at lower and upper portion of the frequency band whereas the lower layer is designed to achieve resonance in the middle of the band. The unit cell of the lower layer of FSS along with an array $(4 \times 4)$ are shown in Fig. 1(c). The unit cell consists of a Jerusalem cross shaped element and a square loop. Such a design allows wide frequency band. The dimensions of this layer as listed in Tab. 3, are chosen so to resonate near the middle of the frequency band.

The transmission and reflection coefficient of the cascaded FSS are plotted in Fig. 3(a). The dual-layer FSS being formed by cascading the two layers with an air gap of $4 \mathrm{~mm}$ in between, reduces the coupling between the two layers leading to such a large bandwidth $(-10 \mathrm{~dB})$. The proposed FSS exhibits transmission below $-10 \mathrm{~dB}$ in the frequency range of $3.04-15 \mathrm{GHz}$, however the $\mathrm{S}_{21}$ level is maintained around $-15 \mathrm{~dB}$ above $10 \mathrm{GHz}$. The reflection coefficient or $S_{11}$ level is close to $0 \mathrm{~dB}$ over the whole frequency band as shown in Fig. 3(a), and thus the resultant dual-layer FSS acts as a good reflector over a large band-

\begin{tabular}{|c|c|c|c|}
\hline Parameter & Value $(\mathrm{mm})$ & Parameter & Value $(\mathrm{mm})$ \\
\hline$L_{\mathrm{t}}$ & 44 & $a$ & 6 \\
\hline$W_{\mathrm{t}}$ & 44 & $b$ & 5 \\
\hline$L_{\mathrm{o}}$ & 10.6 & $c$ & 8.6 \\
\hline$L_{\mathrm{i}}$ & 10 & $S$ & 1 \\
\hline$W_{\mathrm{o}}$ & 10.6 & $t$ & 0.4 \\
\hline
\end{tabular}

Tab. 2. Optimal dimensions of FSS upper layer.

\begin{tabular}{|c|c|c|c|}
\hline Parameter & Value $(\mathrm{mm})$ & Parameter & Value $(\mathrm{mm})$ \\
\hline$L_{\mathrm{b}}$ & 44 & $g$ & 1 \\
\hline$W_{\mathrm{b}}$ & 44 & $M$ & 2.8 \\
\hline$L_{\mathrm{s}}$ & 10.8 & $N$ & 4 \\
\hline$W_{\mathrm{s}}$ & 10.8 & $u$ & 1.1 \\
\hline$P$ & 8.6 & $v$ & 0.6 \\
\hline
\end{tabular}

Tab. 3. Optimal dimensions of FSS lower layer.

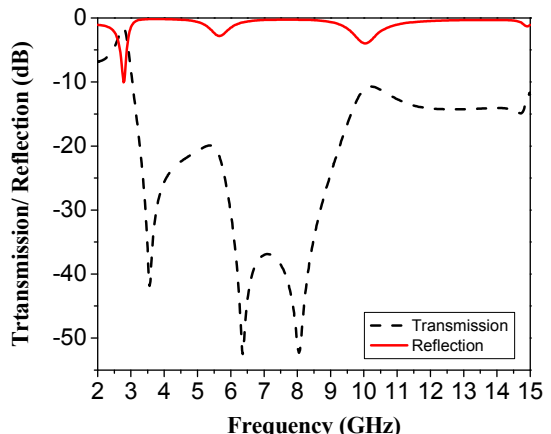

(a)

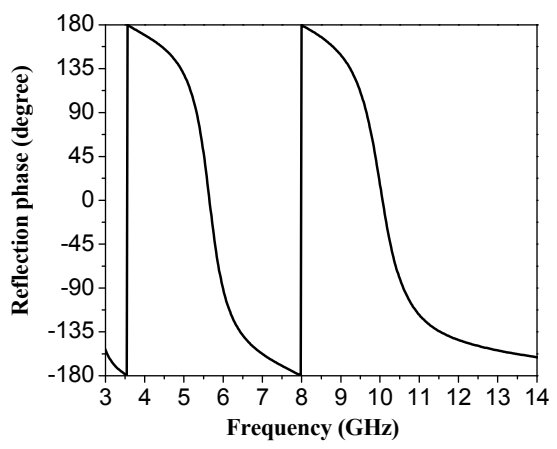

(b)

Fig. 3. (a) Transmission and reflection coefficients, and (b) reflection phase of the cascaded FSS structure.

width. Reflection phase of the cascaded FSS is shown in Fig. 3(b) for an air gap of $4 \mathrm{~mm}$. It is evident that the variation of reflection phase with frequency is nearly linear in the operating band. The linearity is maintained in a piecewise manner from $3.5-8 \mathrm{GHz}$ and from $8-14 \mathrm{GHz}$. The linear variation of reflection phase is extremely useful in enhancing the radiation of bi-directional radiators when placed below the antenna. The waves which are radiated by antenna are reflected by the FSS. If the reflection phase of these reflected waves decreases linearly with frequency (as shown for this design), then the waves radiated directly from the antenna, and the waves reflected by the FSS, are in-phase, and lead to constructive interference. Accordingly the resultant beams get collimated and the antenna gain is enhanced in the broadside direction.

\section{Results and Discussions}

The distance between umbrella shaped antenna element and FSS layer is chosen with a parametric study of the reflection coefficient $\left(S_{11}\right)$ and gain over frequency using CST Microwave Studio simulator. This high frequency simulator is based on Finite Integration Technique (FIT) method and provides both transient and frequency domain responses [21]. The effect of the distance between antenna and FSS, on reflection coefficient and gain of the antenna, is studied, and the characteristics are plotted in Fig. 4. In the parametric study, the distances are chosen close to $23 \mathrm{~mm}$, which is half the wavelength corresponding to center frequency of the band. It is observed from Fig. 4(a) that the antenna with FSS achieves better impedance matching for a distance of $26.5 \mathrm{~mm}$, where $\mathrm{S}_{11}$ is 


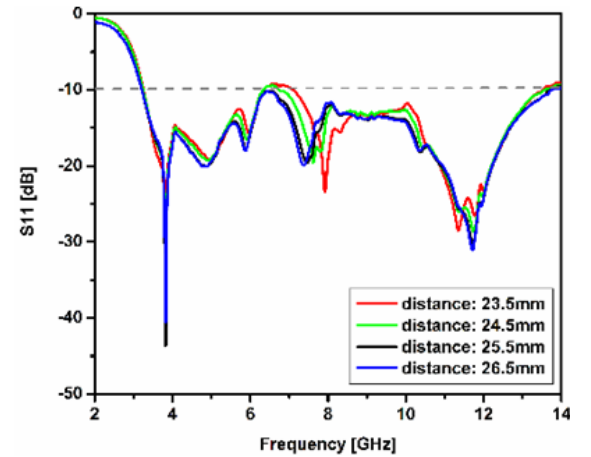

(a)

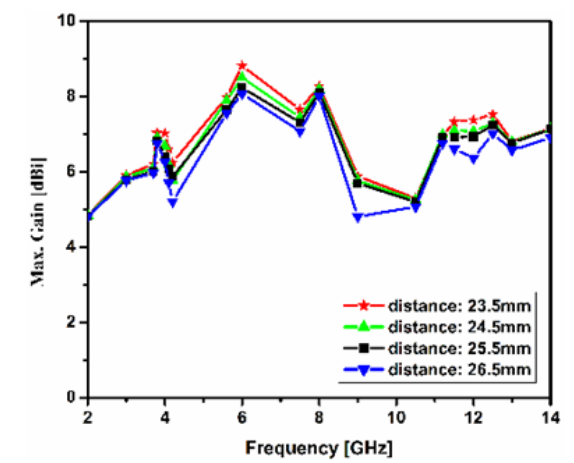

(b)

Fig. 4. (a) Reflection coefficient $\left(\mathrm{S}_{11}\right)$. (b) Peak gain variation with frequency, for the antenna with FSS for different values of distance between them.

below $-10 \mathrm{~dB}$ over the whole band, including $6.5 \mathrm{GHz}$. However from Fig. 4(b), it is observed that the gain enhancement is little bit more between $5-6 \mathrm{GHz}$ for a distance of $23.5 \mathrm{~mm}$ and $24.5 \mathrm{~mm}$. So to maintain both the parameters at a significant level, a distance of $25.5 \mathrm{~mm}$ is chosen as an optimized one.

Simulated surface current flow at $3.8 \mathrm{GHz}$ and $5.5 \mathrm{GHz}$ are shown in Fig. 5. High current concentration along the peripherals of radiating element and feed line with uniformity along y-axis is observed. The surface current distribution on the unit cells of FSS layers when placed below antenna, are shown in Fig. 6 for the upper layer and in Fig. 7 for the lower layer at $3.8 \mathrm{GHz}$ and $5.5 \mathrm{GHz}$. A comparison of $S_{11}$ between antenna with and without FSS by both simulation and measurement is shown in Fig. 8. The antenna provides an impedance bandwidth (reflection coefficient below $-10 \mathrm{~dB}$ ) from 3.1 to $13.1 \mathrm{GHz}$ without FSS and 3.05 to $13.4 \mathrm{GHz}$ with FSS respectively as per the experimental measurement achieved using R\&S ZVL13 vector network analyzer (VNA) [22].

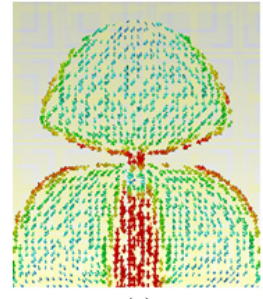

(a)

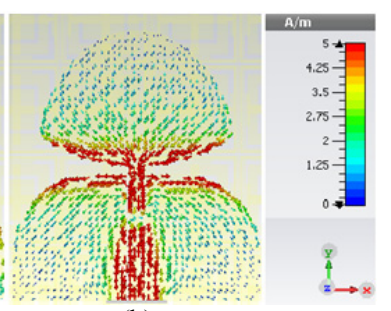

(b)
Fig. 5. Surface current distribution on the antenna at (a) $3.8 \mathrm{GHz}$ and (b) $5.5 \mathrm{GHz}$.

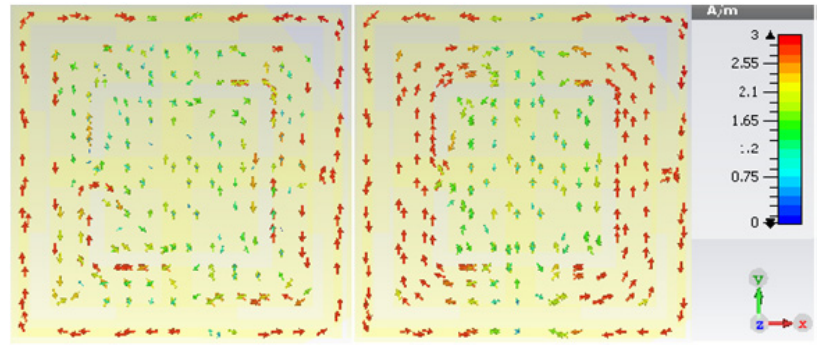

(a)

(b)

Fig. 6. Surface current distribution on the upper layer unit cells of FSS at (a) $3.8 \mathrm{GHz}$ and (b) $5.5 \mathrm{GHz}$.

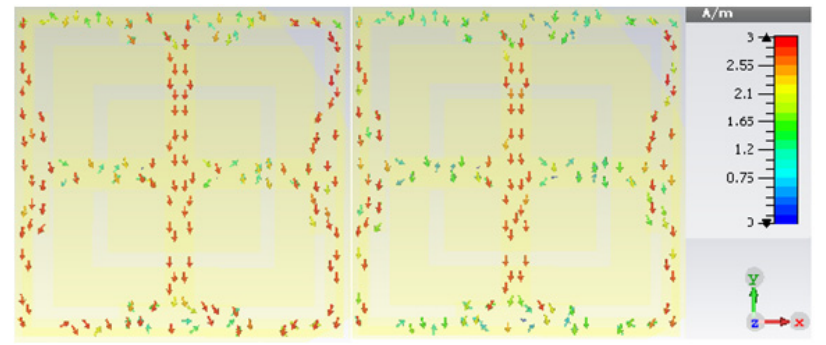

(a)

(b)

Fig. 7. Surface current distribution on the lower layer unit cells of FSS at (a) $3.8 \mathrm{GHz}$ and (b) $5.5 \mathrm{GHz}$.

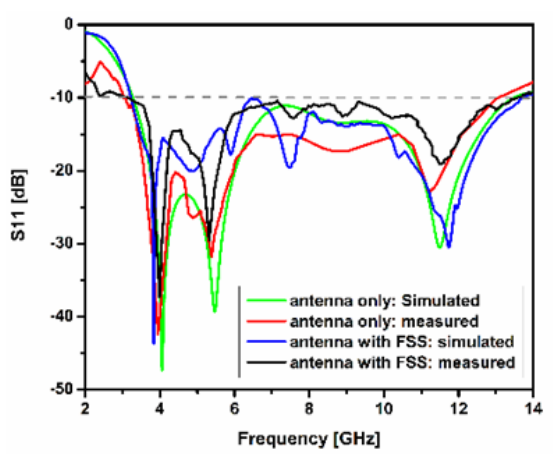

Fig. 8. Simulated and measured reflection coefficient $\left(\mathrm{S}_{11}\right)$ of the antenna with and without FSS layers.

Adequate matching is accomplished as there is agreement between simulated and measured results. Simulated and measured co-polar normalized power patterns in the E-plane and H-plane of the proposed antenna with FSS layers at 3.8, 5.5 and $10 \mathrm{GHz}$ are plotted in Fig. 9. Omnidirectional patterns in the H-plane and proper broadside directive patterns in the E-plane are observed that make antenna suitable for applications like impulse radars and medical imagining. Maximum differences of $6.9 \%$ and $2.66 \%$ between simulated and measured results for E-plane and $\mathrm{H}$-plane pattern plot respectively are observed due to error in fabrication, reflection from surroundings and cable losses during measurement.

A stable gain over the frequency band of operation is a crucial measure for UWB antenna. A gain variation of $\leq 2 \mathrm{~dB}$ in the UWB band is considered as flat or stable. Simulated and measured gain of the proposed antenna with and without FSS layers are plotted in Fig. 10. A gain variation of $2.5-5 \mathrm{dBi}$ is obtained without FSS whereas a gain variation between $5.5-8.5 \mathrm{dBi}$ is obtained with FSS. 


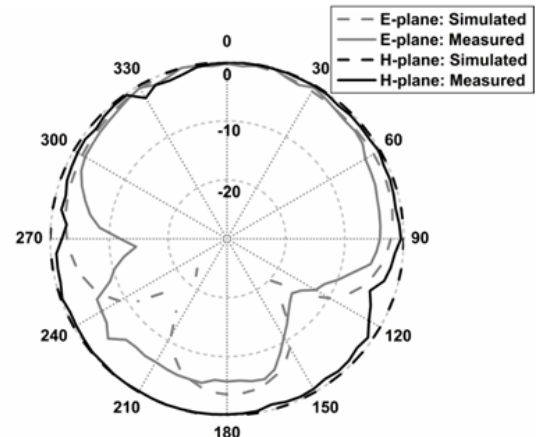

(a)

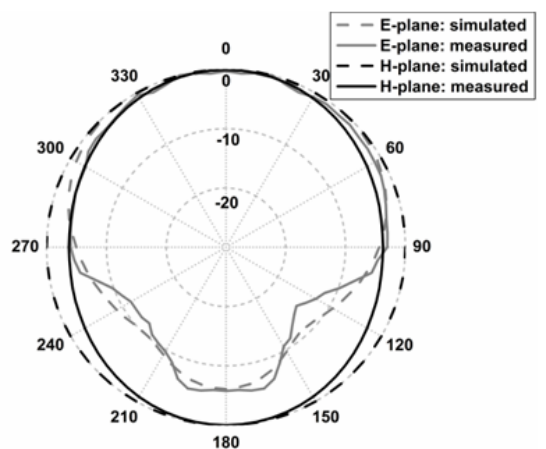

(b)

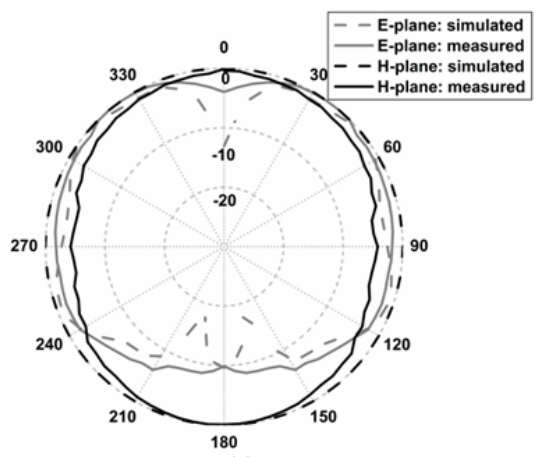

(c)

Fig. 9. Simulated and measured co-polarization radiation patterns of antenna with FSS at (a) $3.8 \mathrm{GHz}$, (b) $5.5 \mathrm{GHz}$ and (c) $10 \mathrm{GHz}$.

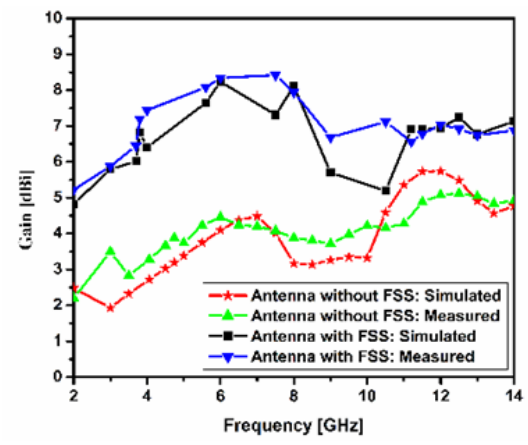

Fig. 10. Peak gain variation with frequency for the antenna with and without FSS layers.

An enhancement of almost $2-4 \mathrm{dBi}$ is achieved in antenna gain in the wide operating band by adding the FSS layers.

Simulated and measured radiation efficiency of the proposed antenna with FSS and without FSS are shown in Fig. 11. The measurement is carried out following the

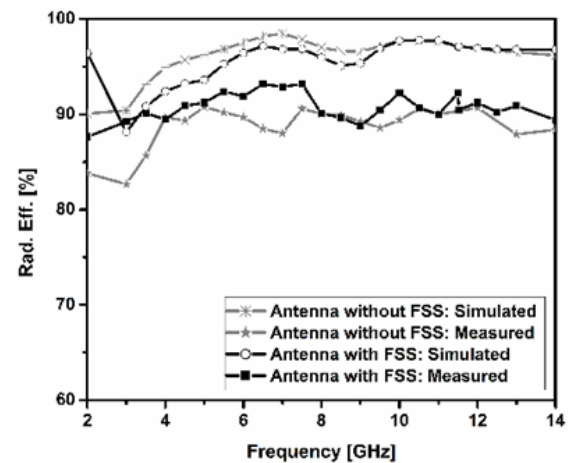

Fig. 11. Simulated and measured radiation efficiency of the antenna with and without FSS layers.

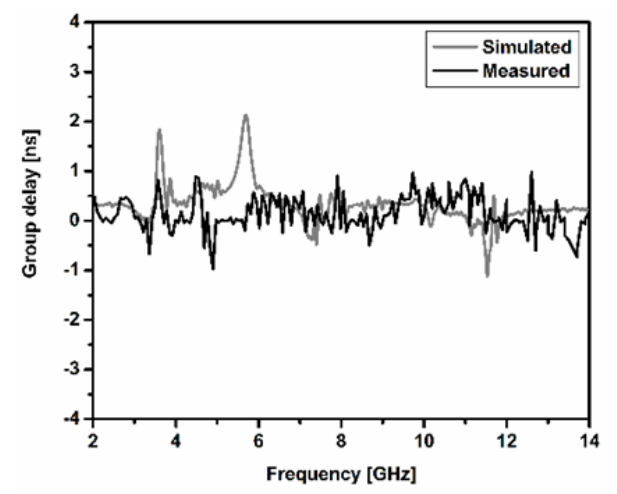

Fig. 12. Simulated and measured group delay of the antenna.

Wheeler's cap method as stated in [23]. The measurement suggests an average radiation efficiency of more than $85 \%$ in the frequency band of $3.05-13.4 \mathrm{GHz}$ without FSS layers whereas the average efficiency is more than $90 \%$ with FSS layers. The difference in measured and simulated radiation efficiency plot establishes the assumption of Wheeler's cap method that considers a gap between the measured values and theoretical values of efficiency. The simulated and measured group delays of the proposed antenna with FSS layers are shown in Fig. 12. Non-varying $( \pm 1 \mathrm{~ns})$ group delay plot suggest a linear phase response and minimal dispersion of the proposed antenna in the operating bandwidth.

\section{Conclusion}

A compact umbrella shaped CPW fed UWB antenna is proposed. Two FSS layers of equal dimensions are kept at the back of the antenna that improve antenna gain by 2-4 dBi over the entire operational bandwidth from 3.05-13.4 GHz with maximum radiation along broadside in E-plane and nearly omnidirectional H-plane pattern. Maximum gain of $8.5 \mathrm{dBi}$ is possible to achieve by optimizing the distance between the antenna and FSS layers. The high antenna gain and maximum radiation in the broadside in the wide bandwidth of $10.35 \mathrm{GHz}$, covering the unlicensed UWB spectrum with more than $90 \%$ radiation efficiency and linear phase response make the antenna well fitted for impulse radar applications such as GPR and applications like wall through imaging, medical imaging. The overall 
dimension of the antenna with FSS layers added becomes $44 \times 44 \times 33.5 \mathrm{~mm}^{3}$. Strategically placement of FSS layers in applications such as GPR can maintain the compactness of the proposed design. The FSS layers can be kept at the back of the antenna by the antenna holder that is usually having larger dimension compared to the antenna. By pursuing this, the effective dimension of the proposed design remains compact as per the size of antenna.

\section{References}

[1] RAIDA, Z., KOLKA, Z., MARSALEK, R., et al. Communication subsystems for emerging wireless technologies. Radioengineering, 2012, vol. 21, no. 4, p. 1036-1049. ISSN: 1210-2512

[2] TATSIS, G., VOTIS, C., RAPTIS, V., et al. Performance of UWB-impulse radio receiver based on matched filter implementation with imperfect channel estimation. In Proceedings of the 7thInternational Conference of the Balkan Physical Union, American Institute of Physics Conference Series. Alexandroupolis (Greece), 2009, vol. 1203, p. 573-578. DOI: 10.1063/1.3322512

[3] TATSIS, G., VOTIS, C., RAPTIS, V., et al. Design and implementation of ultra-wideband impulse radio transmitter. In Proceedings of the 7th International Conference of the Balkan Physical Union, American Institute of Physics Conference Series. Alexandroupolis (Greece), 2009, vol. 1203, p. 579-584. DOI: $10.1063 / 1.3322513$

[4] TATSIS, G., CHRISTOFILAKIS, V., VOTIS, C., et al. BER performance of an ultra-wideband impulse radio correlator receiver. WSEAS Transactions on Information Science and Applications, 2011, vol. 8, no. 10, p. 401-406. DOI: 10.6084/m9.figshare.5096419

[5] FEDERAL COMMUNICATIONS COMMISSION, Washington, D.C. 20554. First Report and Order. 118 pages. [Online] Cited 2001-10-16.

https://transition.fcc.gov/Bureaus/Engineering_Technology/Orders /2002/fcc02048.pdf

[6] LIANG, J., GUO, L., CHIAU, C. C., et al. Study of CPW-fed circular disk monopole antenna for ultra wideband applications. IEE Proceedings.-Microwaves, Antennas and Propagation, 2005, vol. 152, no. 6, p. 520-526.DOI: 10.1049/ip-map:20045179

[7] ABBOSH, M., BIALKOWSKI, M. E. Design of ultrawideband planar monopole antennas of circular and elliptical shape. IEEE Transactions on Antennas and Propagation, 2008, vol. 56, no. 1, p. 17-23. DOI: 10.1109/TAP.2007.912946

[8] SIDDIQUI, J. Y., SAHA, C., ANTAR, Y. M. M. Compact SRR loaded UWB circular monopole antenna with frequency notch characteristics. IEEE Transactions on Antennas and Propagation, 2014, vol. 62, no. 8, p. 4015-4020. DOI: 10.1109/TAP.2014.2327124

[9] LI, M., BIRKEN, R., SUN, N. X., WANG, M. L. Compact slot antenna with low dispersion for ground penetrating radar application. IEEE Antennas and Wireless Propagation Letters, 2016, vol. 15, p. 638-641. DOI: 10.1109/LAWP.2015.2465854

[10] IBRAHIM, A., ALI, W., MACHAC, J. UWB monopole antenna with band notched characteristics mitigating interference with WiMAX. Radioengineering, 2017, vol. 26, no. 2, p. 438-443. DOI:10.13164/re.2017.0438

[11] ALI, W., IBRAHIM, A. A., MACHAC, J. Compact size UWB monopole antenna with triple band-notches. Radioengineering, 2017, vol. 26, no. 1, p. 57-63. DOI: 10.13164/re.2017.0057

[12] SCHNEIDER, J., MRNKA, M., GAMEC, J., et al. Vivaldi antenna for RF energy harvesting. Radioengineering, 2016, vol. 25, no. 4, p. 666-671. DOI: $10.13164 /$ re.2016.0666
[13] MISHRA, R., JAYASINGHE, J., MISHRA, R. G., KUCHHAL, P. Design and performance analysis of a rectangular microstrip line feed ultra-wide band antenna. International Journal of Signal Processing, Image Processing and Pattern Recognition, 2016, vol. 9, no. 6, p. 419-426. DOI: 10.14257/ijsip.2016.9.6.36

[14] FERESIDIS, A. P., GOUSSETIS, G., WANG, S. VARDAXOGLOU, J. C. Artificial magnetic conductor surfaces and their application to low-profile high-gain planar antennas. IEEE Transactions on Antennas and Propagation, 2005, vol. 53, no. 1, p. 209-215. DOI: 10.1109 /TAP.2004.840528

[15] CHEN, H. Y., TAO, Y. Performance improvement of a U-slo patch antenna using a dual-band frequency selective surface with modified Jerusalem cross elements. IEEE Transactions on Antennas and Propagation, 2011, vol. 59, no. 9, p. 3482-3486. DOI: $10.1109 /$ TAP.2011.2161440

[16] YANG, W., WANG, H., CHE, W., WANG, J. A wideband and high-gain edge-fed patch antenna and array using artificial magnetic conductor structures. IEEE Antennas and Wireless Propagation Letters, 2013, vol. 12, p. 769-772. DOI: 10.1109/LAWP.2013.2270943

[17] CHATTERJEE, A., PARUI, S. K. Performance enhancement of a dual-band monopole antenna by using a frequency selective surface-based corner reflector. IEEE Transactions on Antennas and Propagation, 2016, vol. 64, no. 6, p. 2165-2171. DOI: 10.1109/TAP.2016.2552543

[18] CHATTERJEE, A., PARUI, S. K. Frequency-dependent directive radiation of monopole-dielectric resonator antenna using a conformal frequency selective surface. IEEE Transactions on Antennas and Propagation, 2017, vol. 65, no. 5, p. 2233-2239. DOI: 10.1109/TAP.2017.2677914

[19] RUENGWAREE, A., GHOSE, A., KOMPA, G. A novel rugbyball UWB antenna for near-range microwave radar system. IEEE Transactions on Microwave Theory and Technique, 2006, vol. 54, no. 6, p. 2774-2779. DOI: 10.1109/TMTT.2006.874892

[20] ZHANG, J. CAO, P., HUANG, Y., et al. Compact planar ultrawideband antenna with quintuple band-notched characteristics. IET Microwaves, Antennas and Propagation, 2015, vol. 9, no. 3, p. 206-216. DOI: 10.1049/iet-map.2014.0058

[21] COMPUTER SIMULATION TECHNOLOGY (CST), CST Microwave Studio. [Online] Cited 2015-10-26. Available at: https://www.cst.com/Products/CSTMWS. 2015

[22] https://www.rohde-schwarz.com/us/product/zvl13 productstartpage_63493-10575.html

[23] MURAMOTO, M., ISHII, N., ITOH, K. Radiation efficiency measurement of a small antenna using the Wheeler method. Electronics and Communications in Japan, Part I, 1996, vol. 79, no. 6, p. 93-100. DOI: 10.1002/ecja.4410790610

[24] GAO, S., SUN, S., XIAO, S. A novel wideband bandpass power divider with harmonic-suppressed ring resonator. IEEE Microwave and Wireless Components Letters, 2013, vol. 23, no. 3, p. 119-121. DOI: 10.1109/LMWC.2013.2244873

[25] MAJID, H. A., ABD RAHIM, M. K., MASRI, T. Microstrip antenna's gain enhancement using left-handed metamaterial structure. Progress In Electromagnetics Research M, 2009, vol. 8 , p. 235-247. DOI: 10.2528/PIERM09071301

[26] BAYATPUR, F., SARABANDI, K. Miniaturized FSS and patch antenna array coupling for angle-independent, high-order spatial filtering. IEEE Microwave and Wireless Components Letters, 2010, vol. 20, no. 2, p. 79-81. DOI: 10.1109/LMWC.2009.2038517

[27] LI, Y., FENG, Q. A compact tri-band monopole antenna with metamaterial loaded for WLAN/WiMAX applications. Journal of Electromagnetic Waves and Applications, 2013, vol. 27, no. 6, p. 772-782. DOI: 10.1080/09205071.2013.786208

[28] KUNDU, S., JANA, S. K. A compact umbrella shaped UWB antenna for ground-coupling GPR applications. Microwave and 
Optical Technology Letters, 2018, vol. 60, no. 1, p. 146-151. DOI: 10.1002/mop.30928

[29] KUNDU, S., JANA, S. K. Leaf shaped CPW fed UWB antenna with triple notch bands for Ground Penetrating Radar applications. Microwave and Optical Technology Letters, 2018, vol. 60, no. 4, p. 930-936. DOI: $10.1002 / \mathrm{mop} .31075$

[30] KUNDU, S., JANA, S. K. A leaf shaped CPW fed UWB antenna for GPR applications. Microwave and Optical Technology Letters, 2018, vol. 60, no. 4, p. 941-945. DOI: 10.1002/mop.31089

\section{About the Authors ...}

Surajit KUNDU received his B.Tech degree in Electronics and Communication Engineering from the Academy of Technology, West Bengal University of Technology, India in 2009 and M.Tech degree from the Indian Institute of Technology, Kharagpur in 2012. He is pursuing Ph.D. degree from the National Institute of Technology Sikkim, India. His research interest includes antenna design, ultrawideband communication and ground penetrating radar.

Ayan CHATTERJEE received B.Tech. degree in Electronics and Communication Engineering from the West Bengal University of Technology, India, in 2010 and the M.Tech degree in Communication Engineering from University of Kalyani, in 2012. He has submitted his Ph.D. thesis in microwave engineering in November, 2017, at Electronics and Tele-Communication Engineering Dept.,
Indian Institute of Engineering Science and Technology, Shibpur, India. He has more than 15 publications in referred journals and conference proceedings. His research interests include FSS, AMC, slot antenna, and wideband antennas.

Sanjay Kumar JANA received his M.Tech degree from Jadavpur University in 2007 and Ph.D. degree from IIT Kharagpur in 2016. Presently he is working as an Assistant Professor in the Dept. of ECE, NIT Sikkim. His research interests are mainly in broadband and ultra-wideband antenna development, mixed signal \& RFIC design and growth by MBE \& MOCVD and characterization by HRXRD, ECV, Hall\& PL.

Susanta Kumar PARUI received the B.Sc. degree in Physics and B.Tech. degree in Radio Physics and Electronics from the University of Calcutta, India in 1987 and 1990 respectively and the Ph.D. degree in Microwave Engineering from BESU (presently known as the Indian Institute of Engineering Science and Technology), Shibpur, India. Since 2000, he has been associated with the Dept. of Electronics and Tele-Communication Engineering, IIEST Shibpur and presently holds the post of Associate Professor. He is the author of more than 60 papers in referred journals and conference proceedings. His research interests include planar circuits, antennas, DRA, SIW, DGS, EBG, FSS and metamaterials. 